\title{
Disabled medicine
}

\section{Katherine Manders}

$\mathrm{T}$ he disability experience is unique. Because the number of medical students with physical disabilities is so small, each school's experience in dealing with the unique needs of such students is limited. I disclosed my own disability before entering medical school, and afterward found myself unprepared for the need to become an advocate for myself and those who will follow me. Hardest has been the emotional effect over time. This alone was my impetus to write, so that other students in a similar position have a voice.

As a medical student with a physical disability, I decided that it was important to identify how disability is approached and managed in medical school. My approach was to review the limited literature available and begin a dialogue of discussion. Disability can be detailed in many ways, but a commonly cited and inclusive definition comes from the World Health Organization: ${ }^{1}$ "Disability is any restriction or lack (resulting from an impairment) of ability to perform an activity in the manner or within the range considered normal for a human being."

Only a handful of studies have attempted to estimate the prevalence of disability among medical students. The US rate has been estimated at about $0.19 \%,{ }^{2}$ but several questions come to mind: Do schools keep track of students with various disabilities? Do students always disclose their disabilities? Do diabetes mellitus, learning disabilities and paraplegia affect medical-school participation in similar ways? These studies reported low response rates and limited information obtained; the prevalences found may therefore be underestimated.

Because student abilities vary, it has been suggested that technical standards be developed for medical schools. Such standards are important because they provide goals and direction for all those who study or intend to study medicine. Their existence would allow students with disabilities to plan their curriculum, strategize proactively about obstacles and measure progress against a common yardstick. In 1979, the Association of American Medical Colleges (AAMC)'s Special Advisory Panel on Technical Standards for Medical School Admissions published a policy document and identified 5 essential areas of competency (Box 1). ${ }^{3}$ The Canadian Council of Ontarian Medical Schools has subsequently adopted these same 5 general areas. The AAMC panel also set up a medicalschool objectives project and set out that students "must be able to perform a complete physical, perform and interpret diagnostic tests, and respond appropriately to life-threatenf ing medical conditions."

Medical faculty and students were recently surveyed on their opinions of skills necessary within these 5 categories. Overall, respondents rated observation and communication skills as the most valuable: $54 \%$ and $66 \%$ assessed them as "very important," respectively. ${ }^{4}$ Valued more than purely motor skills were technical skills with interpretative compo-
Box 1: Essential areas of competency for medical students

- Observation, including the capacity to combine visual, auditory and tactile information to accurately observe patients

- Communication, including facility in speaking with patients in an effective and sensitive manner; description of a patient's illness or complaint, in writing as well as verbally; and perception of both verbal and nonverbal communication from the patient

- Motor skills, including an ability* to safely perform a physical examination and specific diagnostic tests and procedures to gain information and provide general and emergent care

- Conceptual skills, including faculties to use cognition and memory to analyze and synthesize information, solve problems, and make timely and effective clinical decisions

- Behavioural and social skills, encompassing a range of capacities to develop a mature, sensitive approach to dealing with patients, families and colleagues; perform under stress; recognize one's own physical and emotional limits; show compassion; and display motivation

*Adaptations with respect to tools and approach to physical examination are acceptable, within reason.

nents, such as auscultation or palpation: respondents felt it important to understand the concepts and indications behind such procedures.

Losh and Church ${ }^{5}$ extended the debate of essential skills to cover residency programs. In their article on the essential job functions of family physicians, they acknowledged that residents with permanent disabilities bring a unique perspective and special attributes that enhance patient care. Schools, they stated, need to "maximize opportunities for success while maintaining the integrity of the program." They pointed out medical schools' need to have essential job functions (i.e., those without which neither resident nor faculty member has anything with which to work) documented, and that these "essential functions should be stated as ends rather than means." In their view, finding solutions must be a joint venture between attending physicians, residents and program administrators. Residents play their role by disclosing their disabilities early and requesting whatever accommodations they need.

Although all medical students should have a core group of competencies, should they become "undifferentiated" graduates, which implies that they have the capacity to acquire the knowledge and skills of any specialty? When VanMatre and colleagues $^{4}$ asked those surveyed if they agreed with the idea of the undifferentiated graduate, close to $70 \%$ disagreed. For those who did agree with the concept, they referred to society's right to expect this. To some, a disabled physician is 
viewed as a paradox. In a letter published in The Lancet, ${ }^{6}$ Fielder pointed out that "disability can preclude the study of medicine, but not its practice." The essence of the letter emphasized that not all competencies of general medicine have to be maintained in practice; it depends upon the specialty. A resident who discovers that her bedside manner falls short might, for example, choose to become a pathologist or radiologist; a physician who lost the use of his vision or limbs might choose to practice psychiatry. Fielder pointed out that "lifesaving expertise is vital for some people; for many it is not; and there are other highly valued caring functions that are presently not well met." Quoting from a book by K. Redfield Jamison, ${ }^{7}$ Fielder told of Morag Coate, a British author who recognized the importance of a less prominent skill:

Because the doctors cared, and because one of them still believed in me when I believed in nothing, I have survived to tell the tale. It is not only the doctors who perform hazardous operations or give lifesaving drugs in obvious emergencies who hold the scales at times between life and death. To sit quietly in a consulting room and talk to someone would not appear to the general public as a heroic or dramatic thing to do. In medicine there are many different ways of saving lives. This is one of them.

What voice do students with disabilities have, within a medical school? It is one that varies dramatically and one that is not consistent. In Canada, the United States and Britain, disability legislation is in place to protect the rights of the disabled and to help guide the public in times of change. However, when such laws are adhered to in a black-and-white fashion, the individual whom the act is supposed to protect can become lost. A clear example of this is found in cases involving the Americans with Disabilities Act. ${ }^{8}$ Shomaker ${ }^{9}$ emphasized that decisions need to be made on a case-by-case basis because of the unique needs associated with every disability. A program to support disabled people must work to be flexible while upholding legal and other standards. "We should adapt to those with disabilities not because it is the law, but out of a commitment to our colleagues and human ability." Often, a school's local disability service can act as an advocate for a student. Even though we are in a profession that treats those who are ill, are infirm or have disabilities, we often find it difficult to treat one of our own.

DeLisa and Thomas ${ }^{10}$ recently published io recommendations about the future of medicine and disability. They urged medical schools and residency programs to re-evaluate their programs, technical standards and ability to accommodate people with special needs. They echoed the need for better research and epidemiological studies on disability in medicine. They also encouraged those with disabilities to document their experiences.

When I began this project 2 years ago, I wanted to produce an article that would help my colleagues and generate discussion about disability among those who treat it. I don't have answers to what specific technical skills we should all be able to perform; I don't even think I can define "reasonable accommodation." I can, however, urge medical schools to increase in-class instruction and discussion about disability as well as communication among schools.

This is not an easy road; it cleary has its twists and turns. I hope I have straightened a segment for all of us.

Katherine Manders, formerly a student at the School of Medicine, Queen's University, Kingston, Ont., is now a resident at the Department of Psychiatry, Faculty of Medicine, Dalhousie University, Halifax, NS.

Competing interests: None declared.

Acknowledgements: Dr. R. Garth Smith gave me support and guidance during the preparation of this manuscript. I thank him for his ongoing encouragement and applaud his ability to see beyond the disability in everyone.

\section{REFERENCES}

I. World Health Organization. International Classification of Functioning, Disability and Health (ICF). Geneva: The Organization; 200I.

2. Wu SS, Tsang P, Wainapel SF. Physical disability among American medical students. Am J Phys Med Rehabil I996;75:183-7.

3. Association of American Medical Colleges. Report of the Special Advisory Panel on Technical Standards for Medical School Admission. Washington: The Association; I979.

4. VanMatre RM, Nampiaparampil DE, Curry RH, et al. Technical standards for the education of physicians with physical disabilities: perspectives of medical students, residents, and attending physicians. Am J Phys Med Rehabil 2004;83:54-6o.

5. Losh DP, Church L. Provisions of the Americans with Disabilities Act and the development of essential job functions for family practice residents. Fam Med i999; 31:617-22.

6. Fielder AR. Disability in medical students and doctors [letter]. Lancet 2003;361 (9365):1305-6.

7. Jamison KR. Night falls fast: understanding suicide. New York: Vintage; 2000

8. Americans with Disabilities Act of I99o. Public Law IoI-336. Available: www.dol .gov/esa/regs/statutes/ofccp/ada.htm (accessed 2006 Mar 28).

9. Shomaker TS. The Americans with Disabilities Act and family practice residency programs. Fam Med 1999;31:622-3.

Io. DeLisa JA, Thomas P. Physicians with disabilities and the physician workforce: a need to reassess our policies. Am J Phys Med Rehabil 2005;84:5-I2.

Correspondence to: Dr. Katherine Manders, 1477 Lower Water St., Rm.427, Halifax NS B3J 3Z4; kmandersio@hotmail.com 